\title{
Morphofunctional Categories and Ontogenetic Origin of Temporal Skull Openings in Amniotes
}

\author{
Ingmar Werneburg ${ }^{1,2 *}$ \\ ${ }^{1}$ Senckenberg Center for Human Evolution and Palaeoenvironment (HEP), Eberhard Karls Universität Tübingen, Tübingen, \\ Germany, ${ }^{2}$ Fachbereich Geowissenschaften, Eberhard Karls Universität Tübingen, Tübingen, Germany
}

Keywords: fenestration, emargination, amniote cranial evolution, amniote embryos, musculature

OPEN ACCESS

Edited by:

Michel Laurin

UMR7207 Centre de Recherche sur la

Paléobiodiversité et les

Paléoenvironnements (CR2P), France

Reviewed by:

Juan Carlos Cisneros,

Federal University of Piauí, Brazil

Graciela Helena Piñeiro,

Universidad de la República, Uruguay

Fernando Abdala,

University of the Witwatersrand,

South Africa

${ }^{*}$ Correspondence:

Ingmar Werneburg

ingmar.werneburg@senckenberg.de

Specialty section:

This article was submitted to

Paleontology

a section of the journal

Frontiers in Earth Science

Received: 17 December 2018

Accepted: 28 January 2019

Published: 19 March 2019

Citation:

Werneburg I (2019) Morphofunctional Categories and Ontogenetic Origin of Temporal Skull Openings in Amniotes.

Front. Earth Sci. 7:13.

doi: 10.3389/feart.2019.00013
The rise of phylogenetic systematics (Hennig, 1950) uncovered many natural groups of amniotes with Synapsida-characterized by one temporal opening, and Reptilia (Modesto and Anderson, 2004)-which contains ancestral, typically anapsid groups, without temporal openings, and Diapsida, with two temporal openings and diverse secondary modifications. The ancestrally anapsid parareptiles partly show, with certain ontogenetic, inter-, and intra-specific variation, one opening or marginal excavation in their temporal region (Cisneros et al., 2004; Tsuji and Müller, 2009; MacDougall and Reisz, 2014), although evidence from other characters clearly separates them from Synapsida (Müller, 2004; Tsuji et al., 2012; Brocklehurst et al., 2018). Furthermore, the phylogenetic position of one early "classical" synapsid group (i.e., varanopsids) has become controversial, as it has appeared within Reptilia in some phylogenetic analyses (Ford and Benson, 2018; Laurin and Piñeiro, 2018). Compared to historical classifications (Osborn, 1903; Williston, 1917; Goodrich, 1930), there is a common consensus that temporal openings are only a weak indication for higher taxon interrelationship, although it can be informative on lower taxonomic level (Müller, 2003; Laurin and Piñeiro, 2018; MacDougall et al., 2018). Here, I present a rather morphofunctional categorization of temporal openings, introduce a refined terminology, and provide an ontogenetic explanation on their evolutionary origins.

\section{MORPHOFUNCTIONAL CATEGORIZATION}

\section{I) Anapsid}

The ancestral amniote skull likely had an anapsid shape comparable to the skull of non-amniote groups such as the lungfish with full temporal coverage. Jaw muscles broadly originated from the internal surface of the dermatocranial bones of the temporal region and inserted on the lower jaw (Figure 1I, B, B', C).

\section{II) Monapsid}

When compared to early anapsid tetrapods, temporal openings in amniotes are correlated to higher domed skulls, which provide space for longer, more voluminous, and hence stronger jaw muscles. Partly via tendons, jaw musculature originates mainly from the edges of an opening, which, due to its round shape, provides a greater structural stability than a flat bone (Case, 1924; Frazzetta, 1968; Tarsitano et al., 2001; Werneburg, 2013a). In that way, a different bite performance can be reached on shore. Early fossil Synapsida were predators and herbivores and their temporal opening might have supported the progressing development of stronger jaw musculature for biting (Figure 1-II) (Kemp, 2005; Angielczyck and Kammerer, 2018). Adaptive radiation, later on, resulted in the secondary evolution of diverse feeding modes, correlated to tooth morphology, for example, illustrating that the morphofunctional category of a temporal opening is not a general proxy for feeding ecology. 


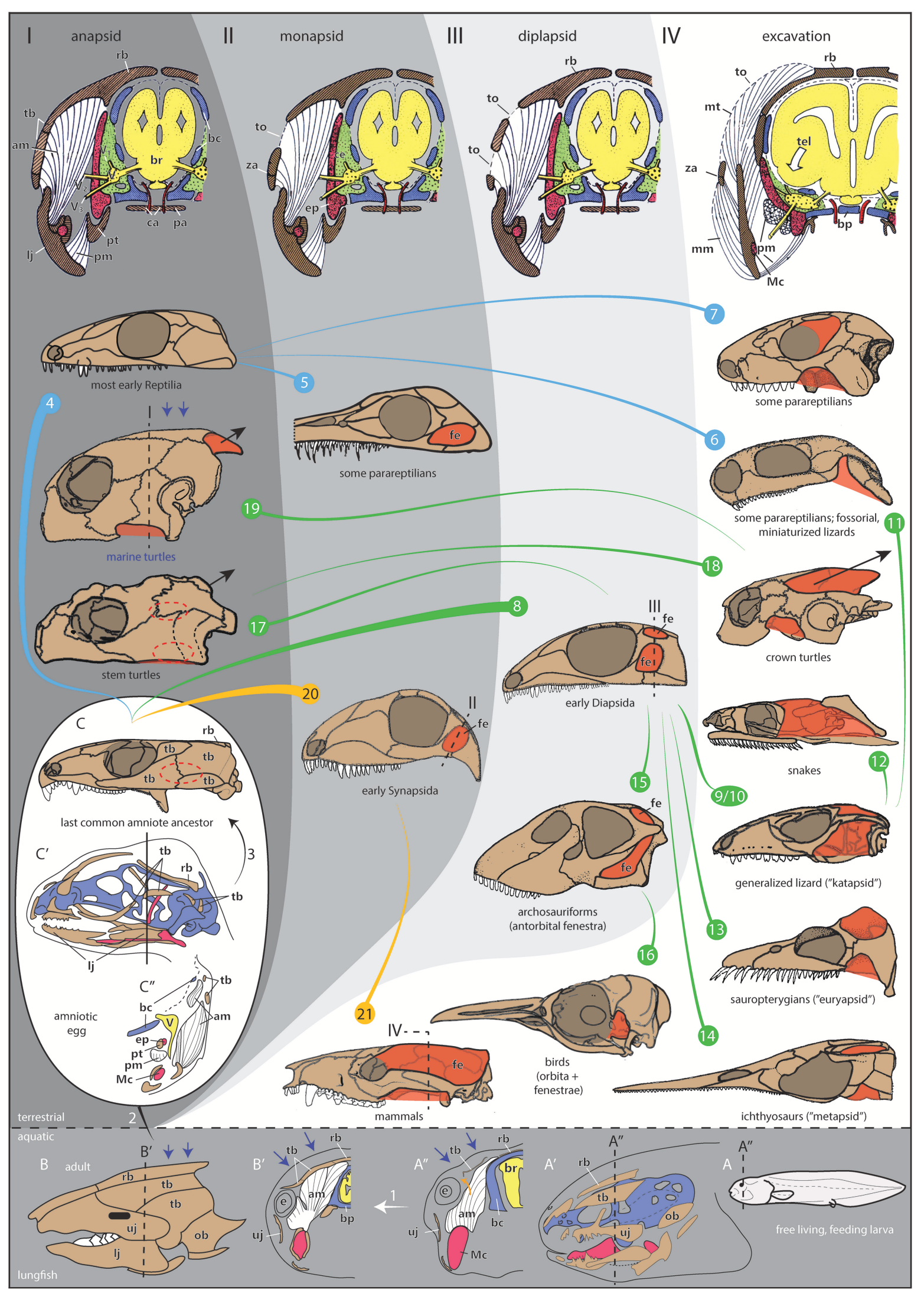


FIGURE 1 | Evolution, development, and morphofunctional categorization of temporal openings in amniotes. (I-IV) Morphotypes with schematic cross sections through the temporal region of amniotes with (I) a pure anapsid morphotype visualized for a generalized early amniote, (II) a monapsid morphotype visualized for generalized early Synapsida, (III) a diplapsid morphotype visualized for generalized Diapsida, and (IV) the excavated morphotype with expanding jaw musculature is visualized for a therian mammal like Monodelphis. Note that the sections show late fetal stages to illustrate the ontogenetic origin of skull elements (chondro-, viscero-, dermatocranium). Section levels in 8, 19, 20, 21 only indicate the rough adult correspondences to these fetal stages. (1-21) Skull shapes of different taxa per morphotype including evolutionary and ontogenetic changes. Note that the color lines between the skulls do not necessarily represent phylogenetic relationships, they just indicate shape transformations within early Reptilia, Diapsida, and Synapsida. Different clades can transform to similar morphotypes (e.g., the ventral excavation type: 6, 11, or the monapsid type: 5, 20). (1) Ontogenetic change in the ancestral anapsid condition of the skull examplified in the Australian lungfish Neoceratodus forsteri. In the free living larva (A, stage 51/52), the skull bones are only little developed $\left(A^{\prime}\right.$, stage 52$)$ and jaw musculature originates from the cartilaginous chondrocranium only $\left[\left(A^{\prime \prime}\right)\right.$ stage 51/52 larva; section level is indicated in $\left(A, A^{\prime}\right)$ ]. Later in development, different bite performance and water pressure (blue arrows) result in the development of a fully formed anapsid temporal skull armor ( $\mathrm{B}$, adult; $\mathrm{B}^{\prime}$, juvenile). For that, the presence of opercular bones as a nearby edge of the temporal region supports an easy closure of the temporal region. The jaw musculature expands and inserts to the fully developed temporal armor (orange arrow). Note that the homologies of the dermatocranial bones are largely unclear between lungfish and tetrapods. Nevertheless, the constructural principals of an encapsuled, anapsid skull are the same in lungfish and early tetrapods. (2) Evolutionary transition from aquatic to terrestrial life with the acquisition of an amniotic egg (large white oval), which is fully independent from aquatic habitat. (3) Ontogenetic change of an amniote inside the egg. The shown embryonic lizard skull $\left(C^{\prime}\right)$ is obviously highly derived but helps visualizing the principle difference to non-amniotic skull development (1), the temporal bones are very small and not fused. The section through the skull $\left(\mathrm{C}^{\prime \prime}\right)$ also illustrates jaw musculature, which is highly differentiated and comes in contact with the small temporal bone precursors. In the last common amniote ancestor (illustrated by a skull of the early reptilian Captorhinus), the region of the late fusing temporal bones is indicated by a dotted oval (C). This area is about to open in later evolution. Whether the earliest amniote actually had a temporal opening or not is difficult to reconstruct (Piñeiro et al., 2012b; Laurin and Piñeiro, 2018). As seen in some early Reptilia, closure of the temporal opening could have happened in postnatal/posthatching ontogeny (Reisz et al., 1984; Haridy et al., 2016). (4) Most early Reptilia, such as captorhinids or pareiasaurs, have a plesiomorphically anapsid skull (examplified by the skull of Palaeothyris herein). (5) In some parareptilian groups, a temporal opening can occur in different places of the temporal region. As such, those belong to the monapsid morphotype, e.g., Australothyris (MacDougall and Reisz, 2014). A recent discussion concerns the anatomy of the temporal region in mesosaurs. As one of the stratigraphically oldest clades of amniotes, they illustrate the rapid radiation of skull shapes in early amniotes. Probably, mesosaurs also had a temporal fenestration as illustrated for Mesosaurus herein [(Huene, 1941; Laurin and Piñeiro, 2017) and references therein], although some concerns about this condition have been raised (MacDougall et al., 2018); but those have been refuted again with strong arguments (Laurin and Piñeiro, 2018). (6) In other parareptiles, such as Eunotosaurus (Keyser and Gow, 1981), one ventral excavation of the temporal region occurs, whether it is derived from an anapsid or a monapsid (or even a diapsid) morphotype is difficult to reconstruct. (7) Several procolophonian parareptiles, such as the illustrated Procolophon, show a orbitotemporal expansion, which represents an emargination of the orbit to possibly serve as refined origin site for the adductor musculature. (8) The clade Diapsida most likely derived from anapsid ancestors. They are characterized by an upper temporal opening related to a broad skull roof, illustrated for Petrolacosaurus (Reisz, 1977). (9) Whether the last common ancestor of Diapsida had a pure diapsid or katapsid morphotype is difficult to reconstruct due to bad preservation of most early Diapsida (Evans, 2008). Within Diapsida, the katapsid skull is most common for lizards, illustrated for Tubinambis. (10) There is a hypothesis that the katapsid skull evolved by the development of a unique lateral jaw adductor muscle, which secondarily suppresses the lower temporal arcade (Rieppel and Gronowski, 1981). (11) Within squamates, fossorial, and miniaturized forms close their upper temporal opening (Rieppel, 1984), such as in Anguis. Their skull morphotype resembles the one shown for some parareptiles herein (6). (12) The upper temporal arcade can be reduced in snakes (illustrated for Nerodia), in which the jaw musculature can travel to the skull roof. $(\mathbf{1 3}, \mathbf{1 4})$ When a lower temporal opening is absent, euryapsid [sauropterygians; illustrated for Cryptoclidus, $(\mathbf{1 3})]$, or parapsid/metapsid [ichthyosaurs; illustrated for Utatsusaurus, (14)] skulls can develop. This is often correlated with high predatory behavior and high jaw muscle power. Partly, also ventral temporal excavations can appear, which likely represent the reduced lower temporal fenestrations (15). In archosauriforms (and mesosaurs), an antorbital fenestra developed making the whole skull, together with the double-fenestrated temporal region, highly grazile. It likely did not serve as insertion site for jaw musculature but might be related to glands, air sacs, flexibility of the snout, and/or reduction of weight (Witmer, 1997; Rayfield, 2004; Weishampel et al., 2004; Piñeiro et al., 2012b,c; Werneburg and Maier, 2019). Illustration shows Shunosaurus (16). In birds, examplified by Eudyptes herein, the temporal openings fuse with the enlarged orbita (17). Turtles most likely evolved within Diapsida and, as such, they must have had ancestors with temporal opening(s) (Schoch and Sues, 2015) (indicated by dashed temporal fenestrae in the illustrated skull of Proganochelys). The stem turtles had an anapsid morphotype, which might have evolved to resist the tensile forces of the neck during the turtlespecific neck retraction (short black arrow) (18). Increased neck retraction (long black arrow) in crown turtles resulted in deep emarginations to best distribute tensile forces (illustrated for Pelomedusa). For that, the ancestral posttemporal fenestra is excavated to form the posterodorsal emargination. The anteroventral emargination appears to be a response to that excavation to permit a bridge-shaped, i.e., stabilizing morphology of the temporal region (Werneburg, 2015). (19) Modern marine turtles, illustrated by Chelonia, reduced neck retraction to a large degree (short black arrow) and, together with water pressure (blue arrows), the temporal excavations largely closed to re-evolve a more or less anapsid morphotype (type I) (Werneburg, 2012). Nevertheless, small emarginations still persist (type IV). (20) Early in amniote evolution, the Synapsida evolved with a stabilized monapsid temporal region (examplified by the skull of Haptodus). (21) Later in synapsid evolution, examplified by Monodelphis herein, the temporal opening shifted dorsad and excavated. As a result, it is fused with the orbit in most mammals [secondarily, the postorbital bar reevolved in primates, for example, incl. Homo] and the ancestral posttemporal fenestra is supressed [a remainder of it can be found as canalis temporalis in monotremes (Schulman, 1906)]. Even a parietal crest can develop as attachment site of the jaw musculature as seen in therocephalians, non-mammaliaform cynodonts, several Mesozoic mammaliaforms and several Theria. It is often lost for enlargement of the skull related with large brains. Color code: White arrow below 1 , ontogenetic change; blue lines, early Reptila taxa; orange lines, Synapsida taxa; green lines, Diapsida taxa; brown, dermal bones; blue, chondrocranium/brain case; red, derivates of the first pharyngeal arch [Meckel's cartilage, epipterygoid/alisphenoid; (Maier, 1989)]; white (in sections), musculature; yellow, nervous system: green, intracranial space (cavum epipterygum); red, blood vessels. Abbreviations: am, jaw adductor musculature; bc, primary braincase wall (derived from chondrocranium); bp, basal plate; br, brain; ca, caroid arteries; ce, cavum epiterygum; e, posteriormost expansion of the eye ball; ep, epipterygoid (alisphenoid in mammals); li, lower jaw; Mc, Meckel's cartilage; $\mathrm{mm}$, masseter jaw adductor muscle in therian mammals; $\mathrm{mt}$, temporalis jaw adductor muscle in therian mammals; ob, opercle bone; pa, palatal bones; pt, pterygoid; pm, pterygoid related musculature; rb, skull roof bones; tel, expansion of telencephalon in therian mammals; tb, temporal dermatocranial bones; to, temporal openings with temporal fascia(e); uj, upper jaw; $V$, trigeminal ganglion; $V_{1}$, nervus olphthalmicus trigemini; $V_{2}$, nervus maxillaris trigemini; $V_{3}$, nervus mandibularis trigemini; za, zygomatic/postorbital arch. Images modified after: (A, A') Ziermann et al. (2018): Figure 2D; (A') Kemp (1999): Figures 12A, 17E; (B) Parker (1899): Figure 229, (B') Ziermann et al. (2018): Figure 2E, (C') Rieppel (1994): Figure 1, (B,C') Rieppel (1987): Figure 3C, (I-IV) Maier and Werneburg (2014): Figures 10.6A-C. Adult skulls after: (C, 17) Gaffney (1990), (4, 8, 20) Carroll (1988), (5-7, 13-15) Benton (2005), (9, 10) Rieppel (1993), (16) Zusi (1993), (18, 19) Gaffney (1979), (21) Novacek (1993). Lungfish embryo staging after Kemp (1982).

Monapsid skulls can also appear in parareptilians and the fenestra can be formed between different bones (Tsuji and Müller, 2009; MacDougall and Reisz, 2014; Laurin and
Piñeiro, 2017). The variable position and shape of the fenestra in different parareptilian taxa suggests diverse jaw muscle attachments and bite performances in that group, 
which included herbivores, carnivores, and insectivors. In many cases, it is not certain whether a "skull hole" is a taphonomic artifact or a real temporal opening (Brocklehurst et al., 2018).

\section{III) Diplapsid}

Diapsida usually have broader skull roofs (Weishampel et al., 2004), which permits an upper temporal fenestra to develop (Figure 1-III) (Tarsitano et al., 2001). Whether a second, lower temporal opening is ancestral for Diapsida is debated (Evans, 2008), but likely (Figure 1-8). When that bar is not present, the skull is called katapsid (Figure 1-9).

Different to the carnivorous and herbivorous early Synapsida, early Diapsida were certainly insectivorous and had to handle the agile food. For that, the edges of two temporal openings (diplapsid condition; I avoid the term 'diapsid' for this morphotype to prevent confusion with the taxon Diapsida similar to 'synapsid'/Synapsida) provided complex attachment sites for a highly differentiated jaw musculature permitting very flexible movements of the jaw apparatus (Holliday and Witmer, 2007; Evans, 2008; Daza et al., 2011). Later in evolution, also other feeding modes evolved within Diapsida, partly associated to comprehensive cranial kinesis (Figure 1-9, 10, 16).

\section{IV) Excavation}

To increase force with longer fibers and to develop more diverse attachment sites, musculature can expand beyond the restrictions of the ancestral temporal anatomy resulting in deep embayments in the dermal skeleton and/or the loss of temporal arcades (Figure 1-IV). Those excavations are known as (a) emarginations, marginal reductions of bones at the edge of the whole temporal region, as well as (b) internal expansions of the temporal fenestrae themselves. Different combinations and degrees of excavations exist, like all morphofunctional categories presented herein are usually fluent.

In different clades of Synapsida, the temporal opening increased in size (Figure 1-21). By suppressing the ancestral posttemporal opening in the occipital region and partly the postorbital bar, the temporalis muscle expands through the temporal fenestra, extends to the external surface of the skull roof and, with that, develops longer muscle fibers to increase bite force. The zygomatic arch serves as origin site for the newly differentiated masseter muscle, enabling chewing along the mammalian stem and leaving an emargination in the arch (Figure 1-21) (Abdala and Damiani, 2004; Werneburg, 2013a; Lautenschlager et al., 2016).

Similar evolutionary patterns can be recognized in some extinct marine reptiles (Figure 1-13, 14), for example, in which the upper temporal opening expands in diameter and even a dorsal parietal crest for the origin of jaw musculature can be developed (Rieppel, 2002), like in several groups of Synapsida. High predatory behavior in the diapsid marine ichthyosaurs and sauropterygians (Liu et al., 2017) might have triggered the dorsal expansion of the jaw musculature and hence the expansion of the upper temporal opening resulting in the secondary modification (i.e., closure and/or emargination) of the lower temporal region as well (Rieppel, 2002). Associated to expanding and hence stronger jaw musculature, a stiffening of the originally kinetic skull toward an akinetic morphology can be recognized (e.g., reduction of basicranial articulation, formation of a secondary braincase wall) (Werneburg et al., 2019).

There is growing consensus that turtles are derived from diapsid (Figure 1-17) reptiles (Rieppel, 2008; Wang et al., 2013; Schoch and Sues, 2015). Neck retraction in stem turtles certainly resulted in the closure of the ancestral temporal opening(s) to resist with a more compact, anapsid skull the tension of the neck musculature in the occipital region (Werneburg, 2015; Werneburg et al., 2015a,b). This novel skull anatomy, consequently, differs from the anapsid skull bone configurations of early Reptilia (Müller, 2003). Crown turtles evolved longer necks and highly elaborated neck retraction modes (Herrel et al., 2008). To resist the resulting increased neck tension, reductions were introduced to the margins of the temporal region, as they provide broader neck-muscle attachment sites that enable better force distribution (Figure 1-18) (Werneburg, 2012, 2015). The posterodorsal emargination, an excavation of the ancestral posttemporal (occipital) fenestra, finally enabled the jaw musculature to expand. This muscle expansion was necessary to bend around the large otic region in modern turtles, which restricts the space inside the adductor chamber (Rieppel, 1990; Werneburg, 2013b; Ferreira and Werneburg, 2019). As a result, although longer, jaw musculature is - different to mammals more narrow and relatively less powerful. As such, it might not trigger the reduction of cranial kinesis in that way (Herrel et al., 2002). Nevertheless, skull stiffening takes place in the turtle stem already (Sterli and De La Fuente, 2010) to resist embryonic neck muscle activity (Werneburg and Maier, 2019).

Large marginal excavations are not only present in Diapsida or Synapsida. They can even be formed within anapsidian parareptiles, including orbital expansions (Figure 1-6, 7).

The temporal openings in diapsids experienced numerous modifications including the reduction or closure of the lower temporal opening (Figure 1-9, 10, 13, 14) (Rieppel and Gronowski, 1981; Reisz et al., 1984), a fusion of both openings with the reduction of the temporal arcades (Figure 112) (Cundall and Irish, 2008), and a fusion of both openings with the expanded orbita (Figure 1-16) (Zusi, 1993). Almost all amniotes, including Diapsida, evolved highly diverse feeding modes, ranging from insectivory and herbivory to piscivory and carnivory, from biting and chewing to filter and suction feeding, among others (Schwenk, 2000; Silva et al., 2017). This illustrates the general and extraordinary functional plasticity of the temporal skull anatomy in amniotes (Müller, 2003), which breaks phylogenetic constrains and opens avenues for the evolution of new skull shapes (Werneburg et al., 2019). To understand diversity of the temporal region, phylogeny appears to be less useful than studies of functional adaptations.

\section{ONTOGENETIC PLASTICITY}

The obviously non-exhaustive and simplified functional categorization of temporal fenestrations presented herein only concerns the more proximate explanations of phylogenetically young functional adaptatations. The ultimate causation in 
the sense of deep time evolutionary change, however, might be detected in life history changes (Sánchez-Villagra, 2012). The majority of non-amniote vertebrates has an anapsid morphotype. Exceptions are chondrichthyans, which lost their dermatocranium completely (Kardong, 2008), some microsaurian lepospondyls (Gee et al., 2019), and batrachian lissamphibians, which, by flattening of their ancestor's skull, largely rearranged their jaw musculature and skull architecture (Rieppel, 1981; Schoch, 2014). The new muscle arrangements in batrachians correlate with the loss of ossification centers through ontogeny as those are no longer recruited as attachment sites through development. This eventually resulted in the complete loss of several "non-used" temporal skull bones in the adults (Schoch, 2014).

Amniotes are characterized by the amniotic egg, which enables complete development of the animal outside an aquatic environment and consequently the invasion of different terrestrial habitats (Sumida and Martin, 1997; Laurin, 2010; Skawiski and Tałanda, 2014; Brocklehurst et al., 2018). With development inside the egg [or, secondarily, inside the mother's womb (Piñeiro et al., 2012a; Werneburg et al., 2016)], the larval stage is lost and more or less fully formed, adult-resembling hatchings leave the eggs (Figure 1C). This is not the case in most extant non-amniotes, in which larvae hatch and have to feed (Figure 1A). For that, jaw (and branchial) musculature inserts primarily to the embryonic neurocranium (chondrocranium), as dermatocranial bones are not yet well-developed (Figure 1 $\mathrm{A}^{\prime}$, $\mathrm{A}^{\prime \prime}$ ) (Edgeworth, 1935; De Beer, 1937; Ziermann et al., 2018). As such, compared to amniotes, the primordial cartilaginous skull is highly functional. Dermatocranial and temporal skull bones are later influenced developmentally by the functional jaw musculature near the neurocranium and are incorporated to the feeding apparatus as further attachment sites (Figure $\mathbf{1 A}^{\prime \prime}, \mathrm{B}^{\prime}$ ) (Ziermann et al., 2018). Furthermore, in non-tetrapods, opercle bones also contribute to the dermatocranial armor to protect gill arches, to regulate gill ventilation, and to form a natural and broad edge of the temporal region (Figure 1 $\mathrm{A}^{\prime}$ : dotted line) (Goodrich, 1930; De Beer, 1937; Kemp, 1999). Temporal bones "just" fill the narrow "gap" between opercle bones and the skull roof.

Also water pressure on the skull in larvae and, if aquatic, in adults might result in the formation of a fully encapsulated skull in non-amniotes (Figure 1A, B) as is indicated by the extant amniotic marine turtles (Figure 1-19). Mesozoic marine turtles such as Toxochelys showed a typical turtle-emargination of the temporal region (Matzke, 2009) related to neck retraction. With the reduced ability of neck retraction and a shorter neck in crown marine turtles, a secondary closure of the temporal armor might also correspond to water pressure (Zdansky, 1923; Werneburg, 2012), a factor not present in pure terrestrial amniotes.

By skipping the larval stage (Figure 1C), the amniote's skull architecture and growth rate differs. The chondrocranium of amniotes becomes less functional for feeding, is hence anatomically more conserved, and the pharyngeal arches are highly modified (De Beer, 1937). The bones not spatially arranged by musculature in early development result in "the embryological failure to close sutures" (Tarsitano et al., 2001). Jaw musculature receives more freedom to diversify and to evolve in response to different feeding requirements as it is non-functional for a long period of development until hatching/birth. Depending on functional demands, just recently developed temporal bones [still losely "floating" on the head's surface (Figure $1 \mathbf{C}^{\prime}$ )] are recruited by the specialized jaw musculature in ontogeny and are spatially arranged to become the newly required attachment sites (Figure $1 \mathrm{C}^{\prime \prime}$ ) (Rieppel, 1987; Fucik, 1991). In that way, generally, apomorphic skull bone mosaics can be explained and, more specifically, the diverse shapes of temporal skull openings can be best interpreted by the functional (future) demands of the developing musculature. As correctly pointed out by the above-mentioned phylogenetic observations, temporal fenestrations between synapsids, parareptiles, and diapsids cannot be homologized (only tissue can): the "holes" in the dermatocranium are just the result of developmental plasticity driven by functional adaptations, which, again and finally, can only be informative on certain taxonomic levels.

At the dawn of amniote evolution, new habitats were invaded and new ecological adaptations were necessary (Sumida and Martin, 1997; Brocklehurst et al., 2018). The great diversity and plasticity of the temporal region of the skull in early amniote taxa of the Permian and Triassic, such as in parareptiles (Figure 14, 5, 6, 7) (Colbert, 1946; Tsuji et al., 2012; MacDougall and Reisz, 2014; Laurin and Piñeiro, 2017), illustrates the rapid adaptive radiation of vertebrates on land (Nuñez Demarco et al., 2018). The monapsid morphotype stabilized in Synapsida (Figure 1-20, 21), whereas an upper temporal opening stabilized in Diapsida (Figure 1-8), although secondary modifications occurred. These are driven by internal and external forces acting on the skull (Gregory and Adams, 1915) as best observable in turtle evolution.

\section{AUTHOR CONTRIBUTIONS}

The author confirms being the sole contributor of this work and has approved it for publication.

\section{FUNDING}

SNF-grant P300PA_164720, DFG-grant WE5440/6-1. The publication costs were mainly covered by the DFGfinanced Open Access Publishing Funds of Universität Tübingen and by Leibniz Association.

\section{ACKNOWLEDGMENTS}

This article is dedicated to Sören Werneburg. I thank Michel Laurin and Graciela H. Piñeiro for the invitation to write this short opinion piece. In addition to them, I thank Fernando Abdala, Robert R. Reisz, and Juan Carlos Cisneros for very useful and controverse comments on the manuscript. Moreover, I thank Oleksandr Yaryhin and Wolfgang Maier for discussion. 


\section{REFERENCES}

Abdala, F., and Damiani, R. (2004). Early development of the mammalian superficial masseter muscle in cynodonts. Palaeontol. Afr. 40, 23-29. Available online at: http://hdl.handle.net10539/13305

Angielczyck, K. D., and Kammerer, C. F. (2018). "Non-mammalian synapsids: the deep roots of the mammalian family tree," in Mammalia. Mammalian Evolution, Diversity and Systematics, eds F. Zachos and R. J. Asher (Berlin: de Gruyter), 117-198.

Benton, M. J. (2005). Vertebrate Palaeontology. Malden, MA: Blackwell Publishing.

Brocklehurst, N., Dunne, E. M., Cashmore, D. D., and Fröbisch, J. (2018). Physical and environmental drivers of Paleozoic tetrapod dispersal across Pangaea. Nat. Commun. 9, 1-12. doi: 10.1038/s41467-018-07623-x

Carroll, R. L. (1988). Vertebrate Paleontology and Evolution. New York, NY: W.H. Freeman and Company.

Case, E. C. (1924). A possible explanation of fenestration in the primitive reptilian skull, with notes on the temporal region of the genus Dimetrodon. Contrib. Museum Geol. Univ. Michigan 2, 1-12.

Cisneros, J. C., Damiani, R., Schultz, C., Da Rosa, A., Schwanke, C., Neto, L. W., et al. (2004). A procolophonoid reptile with temporal fenestration from the Middle Triassic of Brazil. Proc. Roy. Soc. B Biol. Sci. 271, 1541-1546. doi: $10.1098 / \mathrm{rspb} .2004 .2748$

Colbert, E. H. (1946). Hypsognathus, a Triassic reptile from New Jersey. Bull. Am. Museum Nat. History 86, 225-274.

Cundall, D., and Irish, F. (2008). “The snake skull," in Morphology H. The Skull of the Lepidosauria, eds C. Gans, A. S. Gaunt, K. Adler, A. S. Gaunt, and K. Adler (Salt Lake City: Society for the Study of Amphibians and Reptiles), 349-692.

Daza, J. D., Diogo, R., Johnston, P., and Abdala, V. (2011). Jaw adductor muscles across lepidosaurs: a reappraisal. Anat. Rec. Adv. Integr. Anatomy Evol. Biol. 294, 1765-1782. doi: 10.1002/ar.21467

De Beer, G. R. (1937). The Development of the Vertebrate Skull. New York, NY: Oxford University Press.

Edgeworth, F. H. (1935). The Cranial Muscles of Vertebrates. London: Cambridge University Press.

Evans, S. E. (2008). "The skull of lizards and tuatara," in Morphology H. The Skull of the Lepidosauria, eds C. Gans, A. S. Gaunt, and K. Adler (Salt Lake City: Society for the Study of Amphibians and Reptiles), 1-347.

Ferreira, G. S., and Werneburg, I. (2019). "Evolution, diversity, and development of the craniocervical system in turtles with special reference to jaw musculature," in Heads, Jaws and Muscles-Anatomical, Functional and Developmental Diversity in Chordate Evolution, eds J. M. Ziermann, R. E. Diaz, and R. Diogo (Cham: Springer), 171-206.

Ford, D. P., and Benson, R. B. J. (2018). "A redescription of Orovenator mayorum (Sauropsida, Diapsida) using high-resolution $\mu \mathrm{CT}$, and the consequences for early amniote phylogeny," in Papers in Palaeontology. 1-43. doi: $10.1002 /$ spp2.1236

Frazzetta, T. H. (1968). Adaptive problems and possibilities in the temporal fenestration of tetrapod skulls. J. Morphol. 125, 145-157. doi: $10.1002 /$ jmor. 1051250203

Fucik, E. (1991). On the value of the orbitotemporal region for the reconstruction of reptilian phylogeny: ontogeny and adult skull analyses of the chelonian skull. Zoologischer Anzeiger 227, 209-217.

Gaffney, E. S. (1979). Comparative cranial morphology of recent and fossil turtles. Bull. Am. Museum Nat. History 164, 67-376.

Gaffney, E. S. (1990). The comparative osteology of the Triassic turtle Proganochelys. Bull. Am. Museum Nat. History 194, 1-263.

Gee, B. M., Bevitt, J. J., U, G., and Reisz, R. R. (2019). New material of the 'microsaur' Llistrofus from the cave deposits of Richards Spur, Oklahoma and the paleoecology of the Hapsidopareiidae. Peer J. 7:e6327. doi: $10.7717 /$ peerj.6327

Goodrich, E. S. (1930). Studies on the Structure and Development of Vertebrates. London: Macmillan and Co.

Gregory, W. K., and Adams, L. A. (1915). The temporal fossæ of vertebrates in relation to the jaw muscles. Science 41, 763-765. doi: $10.1126 /$ science.41.1064.763

Haridy, Y., MacDougall, M. J., Scott, D., and Reisz, R. R. (2016). Ontogenetic change in the temporal region of the early Permian parareptile Delorhynchus cifellii and the implications for closure of the temporal fenestra in amniotes. PLoS ONE 11:e0166819. doi: 10.1371/journal.pone.0166819
Hennig, W. (1950). Grundzüge einer Theorie der Phylogenetischen Systematik. Berlin: Deutscher Zentralverlag.

Herrel, A., O'Reilly, J. C., and Richmond, A. M. (2002). Evolution of bite performance in turtles. J. Evol. Biol. 15, 1083-1094. doi: 10.1046/j.1420-9101.2002.00459.x

Herrel, A., Van Damme, J., and Aerts, P. (2008). "Cervical anatomy and function in turtles," in Biology of Turtles, eds J. Wyneken, M. H. Godfrey, and V. Bels (Boca Raton: CRC Press), 163-185.

Holliday, C. M., and Witmer, L. M. (2007). Archosaur adductor chamber evolution: Integration of musculoskeletal and topological criteria in jaw muscle homology. J. Morphol. 268, 457-484. doi: 10.1002/jmor.10524

Huene, F. (1941). Osteologie und systematische Stellung von Mesosaurus. Palaeontograph. Stuttgart 92, 45-58.

Kardong, K. V. (2008). Vertebrates: Comparative Anatomy, Function, Evolution. New York, NY: McGraw-Hill Primis.

Kemp, A. (1982). The embryological development of the Queensland lungfish, Neoceratodus forsteri (Krefft). Memoirs Queensland Museum 20, 553-597.

Kemp, A. (1999). Ontogeny of the skull of the Australian lungfish Neoceratodus forsteri (Osteichthyes: Dipnoi). J. Zool. 248, 97-137. doi: 10.1111/j.1469-7998.1999.tb01027.x

Kemp, T. S. (2005). The Origin and Evolution of Mammals. Oxford: University Press.

Keyser, A. W., and Gow, C. E. (1981). First complete skull of the Permian reptile Eunotosaurus africanus Seeley. S. Afr. J. Sci. 77, 417-421.

Laurin, M. (2010). How Vertebrates Left the Water. Berkeley: University of California Press. doi: 10.1525/california/9780520266476.001.0001

Laurin, M., and Piñeiro, G. (2018). Response: commentary: a reassessment of the taxonomic position of mesosaurs, and a surprising phylogeny of early amniotes. Front. Earth Sci. 6, 1-9. doi: 10.3389/feart.2018.00220

Laurin, M., and Piñeiro, G. H. (2017). A reassessment of the taxonomic position of mesosaurs, and a surprising phylogeny of early amniotes. Front. Earth Sci. 5:88. doi: 10.3389/feart.2017.00088

Lautenschlager, S., Gill, P., Luo, Z.-X., Fagan, M. J., and Rayfield, E. (2016). Morphological evolution of the mammalian jaw adductor complex. Biol. Rev. 92, 1910-1940. doi: 10.1111/brv.12314

Liu, J., Organ, C. L., Benton, M. J., Brandley, M. C., and Aitchison, J. C. (2017). Live birth in an archosauromorph reptile. Nat. Commun. 8:14445. doi: $10.1038 /$ ncomms 14445

MacDougall, M. J., Modesto, S. P., Brocklehurst, N., Verriere, A., Reisz, R. R., and Fröbisch, J. (2018). Response: A reassessment of the taxonomic position of mesosaurs, and a surprising phylogeny of early amniotes. Front. Earth Sci. 6:220. doi: 10.3389/feart.2018.00099

MacDougall, M. J., and Reisz, R. R. (2014). The first record of a nyctiphruretid parareptile from the Early Permian of North America, with a discussion of parareptilian temporal fenestration. Zool. J. Linnean Soc. 172, 616-630. doi: $10.1111 /$ zoj.12180

Maier, W. (1989). "Ala temporalis and alisphenoid in therian mammals," in Trends in Vertebrate Morphology. Progress in Zoology, Vol. 35, eds H. Splechtna and H. Hilgers (Stuttgart: Fischer Verlag), 396-400.

Maier, W., and Werneburg, I. (eds.). (2014). Schlüsselereignisse der Organismischen Makroevolution. Zürich: Scidinge Hall Verlag.

Matzke, A. T. (2009). Osteology of the skull of Toxochelys (Testudines, Chelonioidea). Palaeontograph. Abteilung A 288, 93-150. doi: $10.1127 / \mathrm{pala} / 288 / 2009 / 93$

Modesto, S. P., and Anderson, J. S. (2004). The phylogenetic definition of Reptilia. Syst. Biol. 53, 815-821. doi: 10.1080/10635150490503026

Müller, J. (2003). Early loss and multiple return of the lower temporal arcade in diapsid reptiles. Naturwissenschaften 90, 473-476. doi: 10.1007/s00114-003-0461-0

Müller, J. (2004). "The relationships among diapsid reptiles and the influence of taxon selection," in Recent Advances in the Origin and Early Radiation of Vertebrates, eds G. Arratia, M. V. H. Wilson, and R. Cloutier (München: Verlag Dr. Friedrich Pfeil), 379-408.

Novacek, M. J. (1993). "Patterns of diversity in the mammalian skull," in The Skull, Volume 2: Patterns of Structural and Systematic Diversity, eds J. Hanken and B. K. Hall (Chicago: University of Chicago Press), 438-545.

Nuñez Demarco, P. N., Meneghel, M., Laurin, M., and Piñeiro, G. (2018). Was Mesosaurus a fully aquatic reptile? Front. Ecol. Evol. 6:109. doi: $10.3389 /$ fevo.2018.00109 
Osborn, H. F. (1903). On the primary division of the Reptilia into two sub-classes, Synapsida and Diapsida. Science 17, 275-276. doi: 10.1126/science.17.424.275-b Parker, T. J. (1899). A Manual of Zoology. New York, NY: Macmillan and Co.

Piñeiro, G., Ferigolob, J., Meneghel, M., and Laurin, M. (2012a). The oldest known amniotic embryos suggest viviparity in mesosaurs. Historical Biol. 24, 620-630. doi: 10.1080/08912963.2012.662230

Piñeiro, G., Ferigolob, J., Ramosa, A., and Laurin, M. (2012b). Cranial morphology of the Early Permian mesosaurid Mesosaurus tenuidens and the evolution of the lower temporal fenestration reassessed. Comptes Rendus Palevol. 11, 379-391. doi: 10.1016/j.crpv.2012.02.001

Piñeiro, G., Ramos, A., Goso, C., Scarabino, F., and Laurin, M. (2012c). Unusual environmental conditions preserve a Permian mesosaur-bearing Konservat-Lagerstätte from Uruguay. Acta Palaeontol. Polon. 57, 299-318. doi: 10.4202/app.2010.0113

Rayfield, E. J. (2004). Cranial mechanics and feeding in Tyrannosaurus rex. Proc. Roy. Soc. Lond. Ser. B 271, 1451-1459. doi: 10.1098/rspb.2004.2755

Reisz, R. R. (1977). Petrolacosaurus, the oldest known diapsid reptile. Science 196, 1091-1093. doi: 10.1126/science.196.4294.1091

Reisz, R. R., Berman, D. S., and Scott, D. (1984). The anatomy and relationships of the Lower Permian reptile Araeoscelis. J. Verteb. Paleontol. 4, 57-67. doi: 10.1080/02724634.1984.10011986

Rieppel, O. (1981). "Die Funktion des Kragens der Ceratopsida," in Paläontologische Kursbücher. I. Funktionsmorphologie, ed W. E. Reif (München: Paläontologische Gesellschaft Selbstverlag), 205-216.

Rieppel, O. (1984). The upper temporal arcade of lizards: an ontogenetic problem. Rev. Suisse Zool. 91, 475-482. doi: 10.5962/bhl.part.81891

Rieppel, O. (1987). The development of the trigeminal jaw adductor musculature and associated skull elements in the lizard Podarcis sicula. J. Zool. 212, 131-150. doi: 10.1111/j.1469-7998.1987.tb05120.x

Rieppel, O. (1990). The structure and development of the jaw adductor musculature in the turtle Chelydra serpentina. Zool. J. Linnean Soc. 98, 27-62. doi: 10.1111/j.1096-3642.1990.tb01218.x

Rieppel, O. (1993). "Patterns of diversity in the reptilian skull," in The Skull, Volume 2: Patterns of Structural and Systematic Diversity, eds J. Hanken and B. K. Hall (Chicago: University of Chicago Press), 344-389.

Rieppel, O. (1994). Studies on skeleton formation in reptiles. Patterns of ossification in the skeleton of Lacerta agilis exigue Eichwald (Reptilia, Squamata). J. Herpetol. 28, 145-153. doi: 10.2307/1564613

Rieppel, O. (2002). Feeding mechanics in Triassic stem-group sauropterygians: the anatomy of a successful invasion of Mesozoic seas. Zool. J. Linnean Soc. 135, 33-63. doi: 10.1046/j.1096-3642.2002.00019.x

Rieppel, O. (2008). "The relationships of turtles within amniotes," in Biology of Turtles, eds J. Wyneken, M. H. Godfrey, and V. Bels (Boca Raton: CRC Press), 345-353.

Rieppel, O., and Gronowski, R. W. (1981). The loss of the lower temporal arcade in diapsid reptiles. Zool. J. Linnean Soc. 72, 203-217. doi: 10.1111/j.1096-3642.1981.tb01570.x

Sánchez-Villagra, M. R. (2012). Embryos in Deep Time. Oakland: University of California Press.

Schoch, R. R. (2014). Amphibian skull evolution: the developmental and functional context of simplification, bone loss and heterotopy. J. Exp. Zool. B Mol. Dev. Evol. 322, 619-630. doi: 10.1002/jez.b.22599

Schoch, R. R., and Sues, H. D. (2015). A Middle Triassic stem-turtle and the evolution of the turtle body plan. Nature 523, 584-587. doi: 10.1038/nature 14472

Schulman, H. (1906). "Vergleichende Untersuchungen über die TrigeminusMusculatur der Monotremen, sowie die dabei in Betracht kommenden Nerven und Knochen," in Jenaische Denkschriften Semons Zoologische Forschungsreisen in Australien, Vol. 3 (Jena: G. Fischer), 297-400.

Schwenk, K. (ed.). (2000). Feeding: Form, Function and Evolution in Tetrapod Vertebrates. San Diego: Academic Press.

Silva, R. R., Ferigolo, J., Bajdek, P., and Piñeiro, G. (2017). The feeding habits of Mesosauridae. Front. Earth Sci. 5:23. doi: 10.3389/feart.2017.00023

Skawiski, T., and Tałanda, M. (2014). Integrating developmental biology and the fossil record of reptiles. Int. J. Dev. Biol. 58, 949-959. doi: $10.1387 /$ ijdb. $140322 \mathrm{mt}$

Sterli, J., and De La Fuente, M. (2010). Anatomy of Condorchelys antiqua STERLI, 2008, and the origin of the modern jaw closure mechanism in turtles. J. Verteb. Paleontol. 30, 351-366. doi: 10.1080/02724631003617597
Sumida, S. S., and Martin, K. L. M. (eds.). (1997). Amniote Origins. Completing the Transition to Land. San Diego: Academic Press.

Tarsitano, S. F., Oelofsen, B., Frey, E., and Riess, J. (2001). The origin of temporal fenestra. S. Afr. J. Sci. 97, 334-336. Available online at: https://hdl.handle.net/ 10520/EJC97338

Tsuji, L. A., and Müller, J. (2009). Assembling the history of the Parareptilia: phylogeny, diversification, and a new definition of the clade. Fossil Record 12, 71-81. doi: 10.1002/mmng.200800011

Tsuji, L. A., Müller, J., and Reisz, R. R. (2012). Anatomy of Emeroleter levis and the phylogeny of the Nycteroleter parareptiles. J. Verteb. Paleontol. 32, 45-67. doi: 10.1080/02724634.2012.626004

Wang, Z., Pascual-Anaya, J., Zadissa, A., Li, W., Niimura, Y., Huang, Z., et al. (2013). The draft genomes of soft-shell turtle and green sea turtle yield insights into the development and evolution of the turtle-specific body plan. Nat. Genet. 45, 701-706. doi: 10.1038/ng.2615

Weishampel, D. B., Dodson, P., and Osmólska, H. (2004). The Dinosauria. Berkeley, Los Angeles, London: University of California Press.

Werneburg, I. (2012). Temporal bone arrangements in turtles: an overview. J. Exp. Zool. Part B Mol. Dev. Evol. 318, 235-249. doi: 10.1002/jez.b.22450

Werneburg, I. (2013a). The tendinous framework in the temporal skull region of turtles and considerations about its morphological implications in amniotes: a review. Zool. Sci. 31, 141-153. doi: 10.2108/zsj.30.141

Werneburg, I. (2013b). Jaw musculature during the dawn of turtle evolution. Organ. Divers. Evol. 13, 225-254. doi: 10.1007/s13127-012-0103-5

Werneburg, I. (2015). Neck motion in turtles and its relation to the shape of the temporal skull region. Comptes Rendus Palevol. 14, 527-548. doi: 10.1016/j.crpv.2015.01.007

Werneburg, I., Esteve-Altava, B., Bruno, J., Ladeira, M., and Diogo, R. (2019). Unique skull network complexity of Tyrannosaurus rex among land vertebrates. Sci. Rep. 9:1520. doi: 10.1038/s41598-018-37976-8

Werneburg, I., Hinz, J. K., Gumpenberger, M., Volpato, V., Natchev, N., and Joyce, W. G. (2015b). Modeling neck mobility in fossil turtles. J. Exp. Zool. Part B Mol. Dev. Evol. 324, 230-243. doi: 10.1002/jez.b.22557

Werneburg, I., Laurin, M., Koyabu, D., and Sánchez-Villagra, M. R. (2016). Evolution of organogenesis and the origin of altriciality in mammals. Evol. Dev. 18, 229-244. doi: 10.1111/ede.12194

Werneburg, I., and Maier, W. (2019). Diverging development of akinetic skulls in cryptodire and pleurodire turtles: an ontogenetic and phylogenetic study. Verteb. Zool. 69, 113-143. doi: 10.26049/VZ69-2-2 019-01

Werneburg, I., Wilson, L. A. B., Parr, W. C. H., and Joyce, W.G. (2015a). Evolution of neck vertebral shape and neck retraction at the transition to modern turtles: an integrated geometric morphometric approach. Syst. Biol. 64, 187-204. doi: $10.1093 /$ sysbio/syu072

Williston, S. W. (1917). The phylogeny and classification of reptiles. J. Geol. 25, 411-421. doi: 10.1086/622507

Witmer, L. M. (1997). The evolution of the antorbital cavity of archosaurs: A study in soft-tissue reconstruction in the fossil record with an analysis of the function of pneumaticity. J. Verteb. Paleontol. 17, 1-73. doi: 10.1080/02724634.1997.10011027

Zdansky, O. (1923). Über die Temporalregion des Schildkrötenschädels. Bull. Geol. Inst. Univ. Uppsala 19, 89-114.

Ziermann, J. M., Clement, A. M., Ericsson, R., and Olsson, L. (2018). Cephalic muscle development in the Australian lungfish, Neoceratodus forsteri. J. Morphol. 279, 494-516. doi: 10.1002/jmor.20784

Zusi, R. L. (1993). "Patterns of diversity in the avian skull," in The Skull, Volume 2: Patterns of Structural and Systematic Diversity, eds. J. Hanken and B. K. Hall (Chicago: University of Chicago Press), 391-437.

Conflict of Interest Statement: The author declares that the research was conducted in the absence of any commercial or financial relationships that could be construed as a potential conflict of interest.

Copyright $\odot 2019$ Werneburg. This is an open-access article distributed under the terms of the Creative Commons Attribution License (CC BY). The use, distribution or reproduction in other forums is permitted, provided the original author $(s)$ and the copyright owner(s) are credited and that the original publication in this journal is cited, in accordance with accepted academic practice. No use, distribution or reproduction is permitted which does not comply with these terms. 